\title{
Favourable Outcome of a Pregnancy with a Maraviroc-Containing Regimen
}

\author{
Vincent Jeantils ${ }^{1 *}$, Ahmed Tigazin ${ }^{2}$, Eric Lachassine ${ }^{3}$, Anabela Rodrigues ${ }^{2}$, Michelle Bentata ${ }^{4}$ and Gilles Peytavin ${ }^{5}$ \\ 1 Infectious Disease Department, Jean-Verdier Hospital, APHP, Bondy, France \\ ${ }^{2}$ Department of Obstetrics and Gynecology, Jean-Verdier Hospital, APHP, Bondy, France \\ ${ }^{3}$ Paediatric Department, Jean-Verdier Hospital, APHP, Bondy, France \\ ${ }^{4}$ Department of Internal Medicine, Avicenne Hospital, APHP, Bobigny, France \\ ${ }^{5}$ Clinical Pharmacy Department, APHP, Bichat-Claude Bernard Hospital, and EA0449 Paris 7 University, Paris, France
}

\section{Summary}

In developed countries, recommendations do exist concerning the use of highly active antiretroviral therapy during pregnancy of HIV positive women. The choice is easy when the mother is infected with a wild virus or in case of only few genotypic mutations; when multiple genotypic resistances are present or in case of a poor adherence, the treatment choice is more difficult. Concerns exist about the use of new available drugs in pregnancy regarding transplacental passage and foetal toxicity. We report here the first case of the use of CCR5 inhibitor-containing regimen during pregnancy.

Keywords: HIV infection; Antiretroviral agents; Maraviroc; Pregnancy; Multiresistant virus

\section{Case Report}

The advent of highly active antiretroviral therapy (HAART) has substantially increased virological and immunological success rates in HIV cases, with HIV-related deaths reduced by $>85 \%$ in France in 2007 [1]. The most common drug combination consists of two nucleos $(\mathrm{t})$ ide reverse transcriptase inhibitors (NRTI) combined with either a non-nucleoside reverse transcriptase inhibitor (NNRTI) or a boosted protease inhibitor. If HIV becomes resistant to the first-line combination, a change to second line therapy is recommended, which includes preferably at least two (preferably three) fully active agents to combine with an optimized background antiretroviral regimen [2]. A fully active agent is one that is likely to have antiretroviral activity on the basis of the patient's treatment history, drug-resistance testing and/ or a novel mechanism of action.

The outcome of pregnancies in HIV-infected women is often favourable with a rate of mother-to-child transmission at $4 / 1000$ when maternal plasma HIV-RNA load (pVL) is $<50$ copies $/ \mathrm{mL}$ at birth [3]. However, resistance to established therapies in highly treatmentexperienced pregnant women may necessitate the use of newer drugs, raising concerns regarding their safety during pregnancy.

Maraviroc is the first member of a new class of antiretroviral agents, the CCR 5 antagonists. Its antiretroviral efficacy has been demonstrated in treatment-experienced patients with HIV-1 infection [4]. However, clinical data during pregnancy are lacking [5]. Maraviroc is classified as a FDA Pregnancy Category B drug and should be used only if the expected benefit justifies the potential risk to the unborn child [6].

We report the case of a 42-year-old nulliparous HIV-infected woman, with a history of multiple virological failures due to drug resistance, who began a maraviroc-containing regimen $(150 \mathrm{mg}$ twice daily) as part of the MOTIVATE 2 study [4]. Her background therapy included enfuvirtide, boosted fosamprenavir and indinavir, tenofovir and emtricitabine. In December 2005, the date of entry into the trial, her pVL was 340,000 copies $/ \mathrm{mL}$ and CD4+ count was 277 cells $/ \mathrm{mm}^{3}$. After three months of maraviroc treatment, $\mathrm{pVL}$ was $<50$ copies $/ \mathrm{mL}$ and CD4+ count was 412 cells $/ \mathrm{mm}^{3}$. Enfuvirtide was discontinued based on treatment simplification in May 2007 with virological control maintained.
In September 2007, a urine pregnancy test was positive at 10 weeks; the patient was removed from the trial and continued to receive maraviroc from Pfizer France on compassionate grounds. Maraviroc was well tolerated clinically and biologically during the pregnancy. Enfuvirtide was reintroduced during the third trimester due to virological failure related to adherence difficulties.

Despite this reintroduction of enfuvirtide, $\mathrm{pVL}$ was still detectable at levels of 207, 1355 and 2449 copies/mL in three blood tests in the last three months of pregnancy. The last 15 days prior to the elective caesarean section were covered by the addition of raltegravir due to its good diffusion in genital fluids [7]. One week before caesarean, pVL was $<50$ copies $/ \mathrm{mL}$ and CD4+ count was 529 cells $/ \mathrm{mm}^{3}$. The caesarean was performed in April 2008 at 39 weeks of gestation. The treatment was simplified in June 2008 to maraviroc (300 mg twice daily), raltegravir, tenofovir and emtricitabine. In March 2009, her pVL was $<40$ copies/ $\mathrm{mL}$ and CD4+ count was 800 cells $/ \mathrm{mm}^{3}$.

The child was born with no abnormalities, with an Apgar score of $10 / 10$, a birth weight of $2.520 \mathrm{~kg}$, head circumference of $32 \mathrm{~cm}$ and length of $47.5 \mathrm{~cm}$. The placenta was smaller than expected, weighing $331 \mathrm{~g}$, and exhibiting macroscopic and microscopic abnormalities in approximately one-third of the total placenta. Despite a low birth weight, postnatal growth and alertness were normal at 12 months and the child was not HIV-infected.

Maraviroc concentrations in maternal plasma, cord blood and amniotic fluid were determined using high performance liquid chromatography coupled with UV detection (limit of quantitation at 10 $\mathrm{ng} / \mathrm{mL}$ ). The minimum maternal plasma concentration before delivery, assessed 12 hours after the last drug intake, was $937 \mathrm{ng} / \mathrm{mL}$. A second

Corresponding author: Vincent Jeantils, Infectious Disease Department, Hôpital Jean Verdier, Avenue du 14 juillet, 93140 Bondy, France, Tel: +33148026384 E-mail: vincent.jeantils@jvr.aphp.fr

Received October 12, 2011; Accepted December 22, 2011; Published Decembe 26, 2011

Citation: Jeantils V, Tigazin A, Lachassine E, Rodrigues A, Bentata M, et al. (2011) Favourable Outcome of a Pregnancy with a Maraviroc-Containing Regimen. J AIDS Clinic Res 2:134. doi:10.4172/2155-6113.1000134

Copyright: @ 2011 Jeantils V, et al. This is an open-access article distributed under the terms of the Creative Commons Attribution License, which permits unrestricted use, distribution, and reproduction in any medium, provided the original author and source are credited. 
Citation: Jeantils V, Tigazin A, Lachassine E, Rodrigues A, Bentata M, et al. (2011) Favourable Outcome of a Pregnancy with a Maraviroc-Containing Regimen. J AIDS Clinic Res 2:134. doi:10.4172/2155-6113.1000134

determination performed approximately 20 hours after the last maternal intake during the caesarean detected maraviroc concentrations of 231 $\mathrm{ng} / \mathrm{mL}$ in maternal plasma, $76 \mathrm{ng} / \mathrm{mL}$ in cord blood and $187 \mathrm{ng} / \mathrm{mL}$ in the amniotic fluid, which was highly blood-stained. The cord blood to maternal blood ratio was 0.3 , suggesting maternal-to-infant transfer of maraviroc. The consequences of this transfer for the infant's health are as yet unknown.

These results are concordant with the chemical, virological and pharmacokinetic characteristics of maraviroc. Maraviroc is a lowmolecular antiretroviral drug, with $25 \%$ of plasma protein-free fraction, which has been shown in recent reports to penetrate the human genital compartments [8,9]. All values reported in the present report for maraviroc concentrations in maternal plasma, cord blood and amniotic fluid exceeded widely the serum-adjusted EC90 value at $0.57(0.06-10.7) \mathrm{ng} / \mathrm{mL}[6]$.

The presence of placenta abnormalities, clinical preeclampsia and a previous spontaneous abortion in March 2007 suggested a maternal prothrombotic abnormality, although not demonstrated. The placental lesions could not be related to the use of maraviroc since such lesions are also observed in non-HIV infected women.

To our knowledge, this is the first report of maraviroc used prior to and during a human pregnancy. Placental transfer occurred with a cordmaternal ratio of 0.3. No toxic effects were observed at birth or during the child development. However, as with use of other antiretroviral drugs, a potential risk to the unborn child from maraviroc cannot be ruled out.

\section{Acknowledgements}

Editorial support was provided by Ruth Williams of Wolters Kluwer Health, funded by Pfizer. The authors thank Dr Irina Kounourina from Pfizer for her comprehensive help and for providing maraviroc to treat the pregnant patient, and Dr Adyb Baakili from Pfizer who provided maraviroc, before it gained marketing approval in France, for continued treatment of the patient. The authors extend thanks to Dr Kamel Ait Ali from Pfizer for his assistance in preparing this case report for publication.

Dr Bentata was the primary care physician for the patient since 1995. $\mathrm{Dr}$ Jeantils cared for the patient during the delivery period, was in charge of administering pharmacologic treatment during the study and wrote the manuscript.
The obstetrician, Dr Rodrigues, and Dr Bentata monitored the entire pregnancy, and $\mathrm{Dr}$ Tigazin was the physician who performed the caesarean section. Dr Peytavin was responsible for analysis of all of the patient's samples, and reviewed the paper. Finally, Dr Lachassine is the paediatrician who has been providing care for the child since her birth.

\section{Conflicts of interest}

Dr M. Bentata, Dr V. Jeantils, Dr E. Lachassine, Dr A. Rodrigues and Dr A Tigazin have not accepted honoraria or research grants from any pharmaceutical company and do not accept gifts from, nor hold an equity position in any such company. Dr. G. Peytavin has received travel grants, consultancy fees, honoraria and study grants from various pharmaceutical companies, including Abbott, Boehringer-Ingelheim, Bristol-Myers Squibb, Gilead Sciences, GlaxoSmithKline, Janssen, Merck, Pfizer and Roche. The Department of Internal Medicine, Avicenne Hospital, has participated in studies funded by Pfizer.

\section{References}

1. French Hospital Database on HIV (FHDH) - Agence Nationale de Recherche sur le Sida et les Hépatites Virales (ANRS) CO4.

2. Department of Health and Human Services. Guidelines for the Use of Antiretroviral Agents in HIV-1-Infected Adults and Adolescents.

3. Warszawski J, Tubiana R, Le Chenadec J, Blanche S, Teglas JP, et al. (2008) Mother-to-child HIV transmission despite antiretroviral therapy in the ANRS French Perinatal Cohort. AIDS 22: 289-299.

4. Gulick RM, Lalezari J, Goodrich J, Clumeck N, DeJesus E, et al. (2008) Maraviroc for previously treated patients with R5 HIV-1 infection. N Eng J Med 359: 1429-1441.

5. Winters MA, Van Rompay KK, Kashuba AD, Shulman NS, Holodniy M (2010) Maternal-fetal pharmacokinetics and dynamics of a single intrapartum dose of maraviroc in rhesus macaques. Antimicrob Agents Chemother 54: 4059-4063.

6. Celsentri $150 \mathrm{mg}$ and $300 \mathrm{mg}$ film-coated tablets (2008) Summary of Product Characteristics.

7. Jones AE, Talameh JA, Patterson KB, Rezk NL, Prince HA, et al. (2009) FirstDose and Steady-State Pharmacokinetics of Raltegravir in the Genital Tract of HIV Negative Women. 10th International Workshop on Clinical Pharmacology of HIV Therapy, Amsterdam.

8. Dumond JB, Patterson KB, Pecha AL, Werner RE, Andrews E, et al. (2009) Maraviroc concentrates in the cervicovaginal fluid and vaginal tissue of HIVnegative women. J Acquir Immune Defic Syndr 51: 546-553.

9. Kashuba A (2008) Genital tract compartmentalization of orally and topically administered antiretrovirals. $15^{\text {th }}$ Conference on Retroviruses and Opportunistic Infections, Boston, Massachusetts, USA. 